\title{
Comunicação de crise em mídias sociais digitais: um estudo do Twitter, do Facebook e do blog corporativo da Petrobras
}

Communication of crisis in digital social media: a study of the Twitter, of the Facebook and of the Petrobras' corporate blog

Comunicación de crisis en los medios sociales digitales: un estudio del Twitter, del Facebook y del blog corporativo de la Petrobras

Jones Machado

- Doutorando no Programa de Pós-Graduação em Comunicação da Universidade Federal de Santa Maria (UFSM)

- Mestre em Comunicação e bacharel em Relações Públicas pela UFSM

- Membro dos grupos de pesquisa "Comunicação institucional e organizacional" e "WebRP Práticas de relações públicas em suportes midiáticos digitais" (UFSM/CNPq)

-E-mail: jonesm2@outlook.com

Eugenia M. Mariano da Rocha Barichello

- Pós-Doutora pela University College London com bolsa da Capes.

- Doutora e mestre em Comunicação pela UFRJ

- Graduada em Comunicação pela Universidade Federal de Santa Maria (UFSM)

- Professora do Programa de Pós-Graduação em Comunicação e dos cursos de Relações Públicas, Jornalismo, Publicidade e Produção Editorial da UFSM

- Bolsista em Produtividade em Pesquisa do CNPq

- Líder dos grupos de pesquisa "Comunicação institucional e organizacional" e "WebRP - Práticas de relações públicas em suportes midiáticos digitais" (UFSM/CNPq)

• E-mail: eugeniabarichello@gmail.com 


\section{Resumo}

Este artigo tem como objetivo discutir a atuação, em mídias sociais digitais, de uma empresa em situação de crise. Como objeto de estudo, optou-se pela Petrobras, empresa envolvida na "Operação Lava-Jato" da Polícia Federal. Os perfis da empresa no Twitter, na fanpage do Facebook e no blog corporativo representam as mídias digitais mais utilizadas para 0 empreendimento de estratégias de comunicação junto aos seus públicos. A análise, realizada pelo método do estudo de caso e da técnica de observação, tem foco nas postagens relacionadas à investigação judicial que foram publicadas pela Petrobras nessas mídias sociais, nos dois primeiros meses de 2015.

PALAVRAS-CHAVE: COMUNICAÇÃO ORGANIZACIONAL • COMUNICAÇÃO DE CRISE • ESTRATÉGIA DE COMUNICAÇÃO • MÍDIAS SOCIAIS DIGITAIS - PETROBRAS.

\section{Abstract}

This article has the purpose of discussing the performance in the digital social media of a company in a situation of crisis. As a subject-matter of study one opted for Petrobras, the company involved in the "Operação LavaJato" (Jet Wash Operation) conducted by the Brazilian Federal Police. The profiles of the company on the Twitter, on the Facebook fan page and in the corporate blog represent the digital media most used for the implementation of communication strategies with its publics. The analysis, conducted by the case study method and by observation technique, focuses on the posts related to the judicial investigations that were published by Petrobras in such social media during the first two months of 2015.

\section{KEYWORDS: ORGANIZATIONAL COMMUNICATION•CRISISCOMMUNICATION •COMMUNICATION STRATEGY • SOCIAL DIGITAL MEDIA • PETROBRAS.}

\section{Resumo}

Este artículo tiene como objetivo discutir la actuación en los medios sociales digitales, en referencia a una empresa en situación de crisis. Como objeto de estudio se eligió la brasilera Petrobras, empresa envuelta en la "Operación Lava Jato" de la Policía Federal de ese país. Los perfiles de la empresa en Twitter, Facebook y en el blog corporativo representan a los medios sociales digitales más utilizadas para la elaboración de estrategias de comunicación junto con sus públicos. El análisis, llevado a cabo por el método de estudio de caso y de la técnica de observación se centra en los posts relacionados con las investigaciones judiciales, que fueron publicados por la Petrobras en estos medios de comunicación social en los dos primeros meses de 2015. 


\section{ANO 12 • NÚMERO $22 \cdot 1^{10}$ sem. 2015 - ORGANICOM \\ COMUNICAÇÃO DE CRISE EM MÍDIAS SOCIAIS DIGITAIS: UM ESTUDO DO TWITTER, DO FACEBOOK E DO BLOG CORPORATIVO DA PETROBRAS}

\section{$\mathrm{E}$}

m vinte anos da internet comercial no Brasil, marco celebrado em 2015, evidenciam-se, diariamente, reconfigurações no cenário comunicacional, acompanhadas de mudanças culturais, sociais e econômicas na sociedade. Nesse contexto, tanto as organizações midiáticas, quanto as organizações de outros segmentos de mercado, buscam se adaptar às tecnologias, em direção a novos usos e apropriações, respondendo às demandas dos públicos, que também transformaram seu modo de se relacionar e de buscar, produzir, consumir e compartilhar informação.

Segundo a pesquisa Brazil digital future in focus - 2014, realizada pela comScore, o Brasil possui a quinta maior audiência on-line do mundo, sendo o Facebook um dos principais espaços de navegação. Outro estudo ${ }^{2}$ aponta que no mundo, a cada dia, 500 mil pessoas acessam a internet pela primeira vez, são publicados 200 milhões de tweets ${ }^{3} \mathrm{e}$ a cada segundo surge um novo $\mathrm{blog}$. Em face desse cenário, justifica-se olhar para as mídias sociais digitais sob a ótica da comunicação estratégica, a partir da qual a internet não deve ser considerada apenas como uma tecnologia a mais.

A hipótese aqui trabalhada é que, na atual conjuntura, a comunicação digital tem sido utilizada, pelas organizações, para diferentes finalidades na área dos negócios e em diversas situações, como, por exemplo, as crises de imagem às quais estão sujeitas. Ou seja, as mídias sociais são espaços de interação que estão, potencialmente, elencados como vias de comunicação com os stakeholders e, mais do que isso, de monitoramento da situação para a tomada de decisões e insights úteis. A ambiência digital é um espaço de visibilidade e permanente legitimação da marca que precisa atenção e gerenciamento, seja para o contato com a imprensa, seja para se antecipar a ela, sob pena de as crises tomarem proporções irreparáveis.

Assim, este artigo tem como objetivo discutir a atuação em mídias sociais digitais de uma organização em situação de crise. Como objeto de estudo, optou-se pela Petrobras, envolvida na "Operação Lava-Jato" da Polícia Federal, cujo perfil no Twitter ${ }^{4}$, na fanpage do Facebook ${ }^{5}$ e no blog ${ }^{6}$ corporativo são as mídias digitais mais utilizadas, também neste momento, com o empreendimento de estratégias de comunicação junto aos seus públicos. A análise tem foco nas postagens relacionadas à investigação judicial que foram publicadas pela Petrobras nessas mídias sociais, no período correspondente aos dois primeiros meses de 2015.

Para abordar as questões supracitadas, este texto encontra-se dividido em duas partes. Na primeira, é apresentado 0 cenário contemporâneo da comunicação organizacional, que se reconfigura permanentemente com o uso da internet. Aborda-se também a temática da comunicação de crise em mídias digitais e o empreendimento de estratégias com o intuito de legitimação pela empresa. Na segunda, apresenta-se a análise da presença e atuação da Petrobras em mídias sociais digitais, no contexto de crise em que está envolvida atualmente, por meio de um estudo de caso (Yin, 2005) e de observação encoberta não-participativa (Johnson, 2010).

\section{A COMUNICAÇÃO ORGANIZACIONAL EM MÍDIAS SOCIAIS DIGITAIS NO CONTEXTO DE CRISE}

Se no contexto de surgimento das relações públicas era desconsiderada a opinião do público, com o passar do tempo aprendeu-se que ele devia ser informado. Esse processo foi acelerado graças ao desenvolvimento da imprensa e dos meios

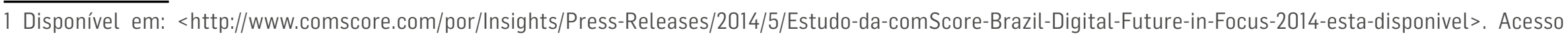
em: 24 fev. 2015.

2 Disponível em: <http://tobeguarany.com/internet-no-brasil/>. Acesso em: 24 fev. 2015.

3 Denominação do texto de 140 caracteres característico do Twitter.

4 Disponível em: <https://twitter.com/petrobras> Acesso em: 24 fev. 2015.

5 Disponível em: <http://www.petrobras.com.br/fatos-e-dados/> Acesso em: 24 fev. 2015.

6 Disponível em: < https://www.facebook.com/petrobras?fref=ts> Acesso em: 24 fev. 2015 
de comunicação, que provocaram alterações na forma como as organizações se relacionam com a sociedade. Nesse cenário, entra em jogo também a construção da imagem das organizações junto aos seus públicos de interesse, que passam a depender em parte das informações veiculadas pela mídia, uma das principais ambiências de visibilidade. No entanto, com a internet, os espaços de visibilidade se multiplicaram, aumentando também os desafios comunicacionais postos aos departamentos de relações públicas.

A informação, considerada matéria-prima da comunicação e fonte de poder, ativa e organiza os elementos envolvidos nas relações da organização com seus públicos (Simões, 2011). Por isso, necessita ser tratada de forma estratégica e planejada, visando ao alcance dos objetivos corporativos e de negócio. Com o crescimento do acesso e do uso estratégico da ambiência digital, esse cenário ganha ainda mais espaço para atuação das organizações em seus negócios, e também para garantirem visibilidade e legitimarem suas ações. E, assim, cada vez mais, as organizações precisam manter relações interativas com públicos específicos, estabelecidas por meio de estratégias de comunicação nesses novos espaços de práticas midiáticas. No cenário da midiatização, a estratégia de presença digital está ligada ao diálogo e à capacidade de atuar em conjunto, constituindo-se num complexo de ações que têm a finalidade de estabelecer relações. Diante disso, as organizações nãomidiáticas passam a explorar os espaços disponibilizados pela internet para se aproximar dos seus públicos de interesse, no intuito de informar a respeito das ações organizacionais; seja apresentando seus projetos, seja retratando-se.

No atual contexto, os sites e as mídias sociais digitais - incluindo-se, aqui, os blogs - tornam-se mídias institucionais de referência para o público, fazendo frente à atuação da mídia tradicional. Nesses espaços da internet, o processo de construção da visibilidade passa por uma desintermediação, à medida que a comunicação organizacional estratégica atua na direção de garantir o alcance de seus objetivos com o enfoque ideal, visto que detém o controle de determinado aparato tecnológico, ou seja, atua junto às mídias sociais digitais e aos sites/hotsites/portais institucionais. 0 conceito de desintermediação aqui utilizado tem é de Carlos Alberto Scolari (2009) e refere-se ao processo de não-utilização das mídias tradicionais para a construção da visibilidade.

No entanto, há duas faces nessa nova visibilidade (Thompson, 2008), uma vez que foram criados espaços para retratações públicas, formas de antecipação à imprensa e de aproximação com o público; mas, também, novos riscos surgiram com isso. Ao mesmo tempo em que as práticas organizacionais podem ser potencializadas graças à comunicação midiática, as fragilidades podem vir à tona, em grande parte em consequência do papel ativo dos interagentes. Atualmente, quase tudo está exposto ou tornado público por meio de multimídias utilizadas pelas empresas: os escândalos políticos, as gafes, as manifestações, os erros em balanços financeiros, o vazamento de informações, os recalls de produtos, entre tantas outras crises de impacto na imagem e reputação das organizações e que são amplificadas na ambiência digital.

Diante do exposto, e remontando ao contexto do surgimento e avanço das relações públicas, hoje as empresas estão nuas (Tapscott; Ticoll, 2005); o público exige que as organizações sejam transparentes, informando suas práticas, seus projetos de responsabilidade social e ambiental, seus balanços financeiros e tudo o que mais fazem para manter seus negócios ou para contribuir com a sociedade. Todas as informações que forem divulgadas pela e/ou sobre a organização irão influenciar na formação da imagem pelos cidadãos, que poderá influenciar na decisão de compra de um produto ou contratação de um serviço e até mesmo na recomendação para outras pessoas. Se a organização for pública, estatal, ou de capital aberto, a visibilidade das ações e a transparência da gestão precisam ser redobradas, já que a imagem é a organização vista pelos olhos do seu público e está relacionada ao valor simbólico e à credibilidade das organizações, sendo um dos principais ativos a serem zelados pelas empresas no mercado, visto que se refere a um fator de competitividade. Por isso, eventos críticos que envolvem a organização, tais como desvio de recursos, acidentes aéreos, má gestão e poluição do meio ambiente, entre 
outros, demandam hoje por um gerenciamento ainda mais rápido e efetivo, tendo em vista a velocidade da difusão das notícias, via internet e a globalização dos mercados. Nos últimos anos, acompanhou-se em multimídias a ampla cobertura midiática de pelo menos três situações catastróficas, a saber, os casos British Petroleum (2010), Chevron (2011) e Malaysia Airlines (2014), as quais também tiveram ampla repercussão nas mídias sociais.

Os efeitos de uma crise ultrapassam as "fronteiras" da sede da organização, impactando não somente as transações dela e de seus acionistas, como também os investimentos de governos, fornecedores, bancos etc. e, por consequência, o cotidiano da sociedade. Segundo o Instituto para Gestão de Crises norte-americano, as crises organizacionais são "uma perturbação significativa na organização que provoca uma extensa cobertura da mídia. 0 escrutínio público sobre o ocorrido pode afetar as operações normais da organização e também ter um impacto político, jurídico, financeiro e governamental sobre o negócio"7.

No entanto, embora as organizações devessem ter um plano de gestão de crises, elaborado por uma equipe multidisciplinar, a realidade mostra o contrário. Principalmente em alguns ramos de atuação em que a probabilidade de uma crise é grande, a previsibilidade deveria ser levada em conta pela equipe administrativa a fim de resguardar a imagem e a reputação da marca. Nesse contexto, à medida que uma organização tem um plano de contingenciamento de situações negativas, ela tem a possibilidade de aprender mais e explorar favoravelmente o ocorrido, fortalecendo-se. Robert Ulmer, Timothy L. Sellnow e Matthew Seeger (2007, p. 4) argumentam que,

\begin{abstract}
de fato, o nosso entendimento é que as crises podem realmente promover um posicionamento positivo para a organização. Nós vemos as crises como oportunidades para aprender e melhorar, vendo as crises como elas são percebidas na cultura chinesa, onde seu símbolo em mandarim é interpretado como uma 'perigosa oportunidade'. Pela natureza, as crises são momentos perigosos no ciclo de vida de uma organização; todavia as mesmas promovem oportunidades com o potencial de tornar a organização mais forte do que antes da própria crise ${ }^{8}$.
\end{abstract}

Nesse processo de crise, aumenta a atuação do profissional de relações públicas, que também tem a oportunidade de legitimar-se como gestor da comunicação organizacional. A comunicação é imprescindível nesses momentos e o relaçõespúblicas é quem detém as competências para evitar boatos, facilitar o fluxo de informações e gerir a imagem.

Com a comunicação em rede, a organização em crise fica ainda mais exposta, demandando uma tomada de decisões ágil e assertiva. Para essa mudança de cenário, exige-se adaptação com a mudança da estratégia a ser aplicada. Rafael A. Pérez (2012, p. 203) indica que transformar uma realidade indesejada em um futuro almejado, implica considerar novas ferramentas, novas abordagens, eleger rotas, além de compreender que "a comunicação deixa de ser um recurso estratégico para ser um elemento constituinte da própria estratégia".

Nesse sentido, entendendo que os públicos querem participar e a abordagem deva ser ética, relacional e humana, três concepções de enfoque político de Roberto P. Simões (2011) podem ser aplicadas ao contexto digital. Como uma "via de mão dupla", as relações públicas auxiliam para que tanto a organização quanto o interagente gerem informações e interajam por meio da ambiência da internet, numa ação recíproca. Ainda, a partir do entendimento de que a organização é como uma "casa de vidro", a lógica é que não haja mistérios ou impedimentos de informações e fatos, visto que atualmente há uma visibilidade natural e "obrigatória", por causa do maior interesse público na transparência organizacional. Também, sob a perspectiva da distribuição de poder, a organização pode adotar uma "política de portas abertas", de forma que o público possa conhecê-la, ser ouvido e participar, sugerindo, criticando ou decidindo.

7 Disponível em: <http://www.crisisexperts.com/2008CR.pdf>. Acesso em: 24 fev. 2015.

8 Tradução nossa. 
No entanto, cabe à empresa pensar e eleger sua abordagem, suas ferramentas e sua estratégia de posicionamento e estratégia de comunicação efetiva diante de uma crise de imagem. Tratando-se de um ambiente fluido e veloz, como 0 que se vive atualmente, as decisões empresariais devem ser ágeis e realizadas em sinergia, num contínuo processo de pensamento e intuição. Considerando as mídias sociais digitais como opções de pontos de contato e comunicação com os públicos, existe a possibilidade de se lançar mão de uma estratégia digital que contemple uma convergência midiática e de conteúdos, articulando os ambientes on-line e off-line.

\section{A ATUAÇÃO DA PETROBRAS EM MULTIMÍDIAS DIGITAIS}

A fim de dar conta do objetivo desta pesquisa, selecionou-se um aporte metodológico composto pelo método do estudo de caso (Yin, 2005) e pela técnica da observação encoberta não participativa (Johnson, 2010). Com relação ao método de pesquisa, decidiu-se por adaptar a proposta de Yin (2005) para descrição e análise em plataformas digitais. Neste estudo, a abordagem se justifica, pois busca-se entender "como" a Petrobras faz uso de seus espaços digitais institucionais no período de crise. Nessa direção, as teorias norteadoras do estudo serão articuladas ao longo do processo analítico, a fim de que os referenciais teóricos selecionados sirvam de guia para as análises empreendidas acerca dos dados coletados.

Para a definição do corpus de pesquisa, as fontes de evidência para a coleta de dados foram: 1) observação encoberta e nãoparticipativa nas interfaces gráficas em mídias digitais; e 2) documentação, ao considerar os recortes das interfaces das mídias sociais digitais as quais a empresa utiliza disponíveis na internet. Neste estudo, a compreensão do processo está delimitada à análise das postagens realizadas pela empresa no período que compreende os dias $1^{1}$ de janeiro a 1ํㅡㄹ de março de 2015, no Twitter, no Facebook e no blog corporativo, totalizando sessenta dias de análise do período de maior visibilidade e repercussão da crise.

A escolha por esse tipo de observação se justifica pelo fato de que o pesquisador não participa de nenhuma relação com a empresa no ambiente sob investigação, sem quaisquer atos que desconfigurem a abordagem, como a realização de comentários e compartilhamento de conteúdo postado pela empresa, postagem de conteúdo em perfil ou envio de mensagem por qualquer um dos espaços para contato. Dessa forma, a observação é de caráter não-obstrutivo, ou nãoreativo, em que a organização desconhece o fato de estar sendo pesquisada, a fim de não influenciar o andamento da análise dos dados coletados em ambientes digitais em que a Petrobras empreende estratégias de comunicação.

Com a finalidade de apreender o objeto empírico de estudo, parte-se para sua descrição, análise e articulação com o referencial teórico convocado e discutido anteriormente neste artigo. Para a análise, serão consideradas quatro estratégias identificadas a prioripor meio de análise flutuante do corpus selecionado: 1) interação; 2) visibilidade; 3) transparência; 4) legitimação.

A Petrobras é a maior empresa do Brasil e está entre as dez maiores do mundo no setor, fazendo-se presente em dezessete países, com atuação nas atividades de exploração de petróleo e gás, produção, refino, comercialização, transporte e petroquímica, distribuição de derivados, gás natural, biocombustíveis e energia elétrica. Criada em 1953, é uma sociedade anônima de capital aberto, que congrega aproximadamente 86 mil empregados e cerca de 800 mil acionistas, tendo como acionista majoritário a União Federal. Líder do setor petrolífero brasileiro, é a empresa brasileira que mais gera patentes no país e no exterior, devido às constantes pesquisas e ao desenvolvimento de tecnologias para o desempenho de suas funções, condição essa que the tem conferido o pioneirismo e a inovação em diversos casos na sua área de atuação, como exploração em águas profundas e ultraprofundas. 


\section{ANO $12 \cdot$ NÚMERO $22 \cdot 1^{10}$ sem. $2015 \cdot$ ORGANICOM \\ COMUNICAÇÃO DE CRISE EM MÍDIAS SOCIAIS DIGITAIS: UM ESTUDO DO TWITTER, DO FACEBOOK E DO BLOG CORPORATIVO DA PETROBRAS}

Na Petrobras, há um núcleo específico dentro da Gerência de Comunicação Institucional, dedicado à gestão da presença digital da Companhia, levando em conta o seu plano global e um plano específico para cada uma das mídias sociais digitais ou outras plataformas/canais em que está presente. Além da equipe interna, existem também agências digitais, de monitoramento, de SEO/SEM ${ }^{9}$ e uma produtora audiovisual que prestam serviços à empresa. Toda a atuação leva em conta os objetivos estratégicos do Plano de Negócios da Companhia e do Plano Integrado de Comunicação anual (Machado, 2012).

A partir de dispositivos sociotécnicos digitais, possibilitados pela ambiência da internet, a Petrobras investe na sua comunicação organizacional lançando mão de estratégias como adesão ao uso de um portal, presença em nove mídias sociais digitais, incluindo a plataforma de $b \log$. São mais de 35 sites específicos, alguns hotsites de promoções, aplicativos sociais, aplicativos móveis e games, utilizados para diversas finalidades, seja divulgação, interação, entretenimento, marketing ou informação.

Figura 1-Petrobras nas redes

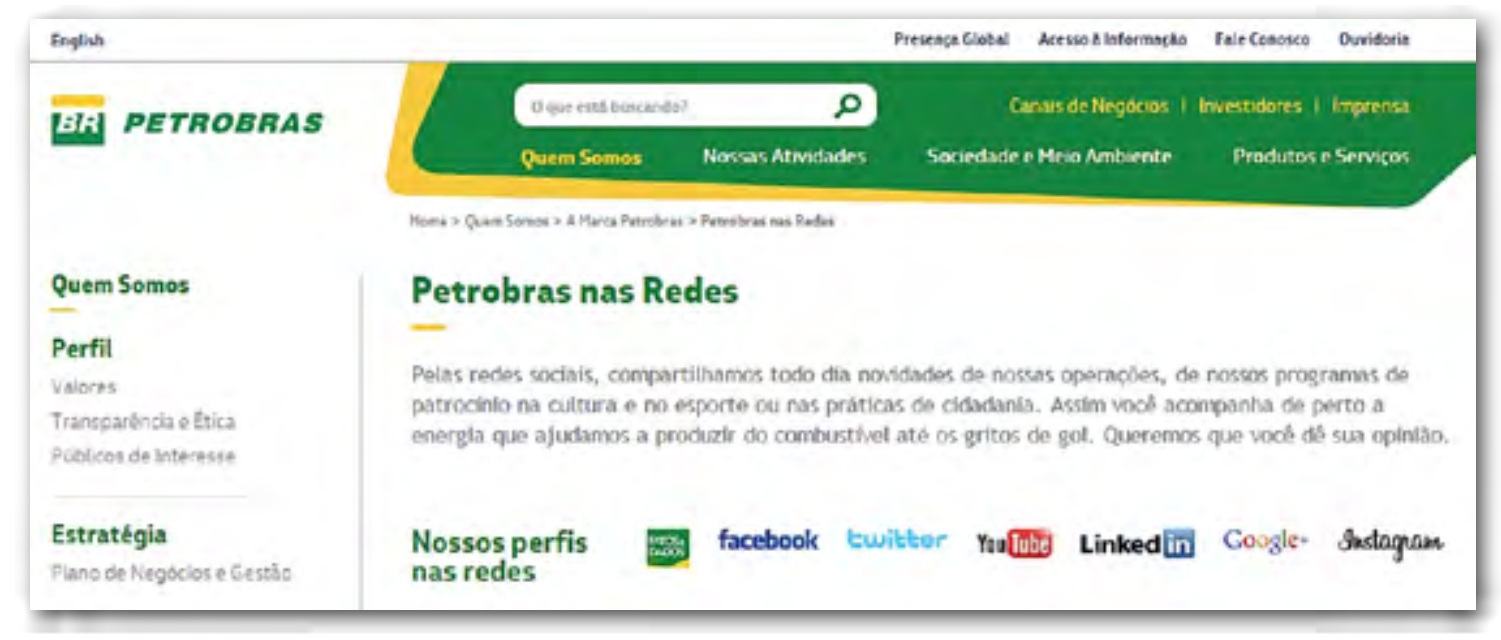

Fonte: Petrobras ${ }^{10}$

Para fins de identificação, são considerados os principais canais oficiais da companhia o portal institucional (http://www. petrobras.com.br/pt/), a fanpage no Facebook (www.facebook.com/fanpagepetrobras), o canal no site de vídeos YouTube (www.youtube.com/canalpetrobras), o perfil no Twitter (www.twitter.com/petrobras), o canal de compartilhamento de imagens no Flickr (http://www.flickr.com/petrobras), o blog corporativo Fatos e Dados (http://www.petrobras.com.br/fatose-dados/), o perfil para postagens de imagens no Instagram (https://instagram.com/petrobras/), a página de publicações institucionais no Issuu (http://issuu.com/petrobrasmagazine), o perfil no Google+ (https://plus.google.com/+petrobras/ posts) e a conta para compartilhamento de apresentações em slides no Slideshare (http://pt.slideshare.net/petrobrasri). No contexto de crise que a Petrobras atravessa identificaram-se três destes espaços digitais como sendo os mais utilizados, com publicações diárias relacionadas à conjuntura: o perfil no Twitter, a fanpage no Facebook e o blog corporativo Fatos e Dados, os quais fazem parte do corpus desta análise.

A "Operação Lava-Jato", deflagrada em março de 2014, em diversos estados brasileiros, investiga um suposto esquema de lavagem e desvio de dinheiro, que envolve empreiteiras nacionais, políticos brasileiros e a maior empresa do país - a Petrobras, a maior prejudicada. Tendo sua imagem e reputação arranhadas pelas denúncias e investigações, além dos resultados financeiros negativos, a companhia figura na imprensa internacional e inclusive nos tribunais norte-americanos. Quase dez meses depois do início da referida operação, sob pressão da população e dos acionistas, a presidente e mais cinco diretores da companhia foram substituídos, em meio à maior crise de credibilidade enfrentada pela empresa. Para fazer 


\section{ANO $12 \cdot$ NÚMERO $22 \cdot 1^{10}$ sem. $2015 \cdot$ ORGANICOM \\ COMUNICAÇÃO DE CRISE EM MÍDIAS SOCIAIS DIGITAIS: UM ESTUDO DO TWITTER, DO FACEBOOK E DO BLOG CORPORATIVO DA PETROBRAS}

face a esse cenário turbulento, a Petrobras parece lançar mão de estratégias que a auxiliem a amenizar a crise e resgatar a confiança da sociedade nessa maior empresa do país.

A seguir, será analisada a atuação da Petrobras em mídias sociais digitais, a partir de quatro indicadores identificados previamente como estratégias de comunicação: 1) interagir com os públicos de interesse, 2) dar visibilidade às ações cotidianas, 3) garantir a transparência dos fatos; e 4) buscar manter a legitimação da marca junto à sociedade.

0 espaço digital mais importante e mais valorizado é o blog corporativo Fatos e Dados. Criado em 2009, como estratégia de comunicação em meio a uma crise anterior à atual, é hoje destino de links dos demais espaços de comunicação, com destaque no site oficial, sendo referência para a imprensa e com espaços específicos sobre a "Operação Lava-Jato". Nele, a Petrobras apresenta o seu ponto de vista sobre os fatos e apresenta os dados para estabelecer um contato direto com seus públicos de interesse e com as empresas midiáticas, que muitas vezes são pautadas pelo blog, mostrando o processo de desintermediação pelo qual passa a informação e a mudança na lógica da construção e divulgação da notícia.

Figura 2 - Resposta à imprensa pelo blog Fatos e Dados

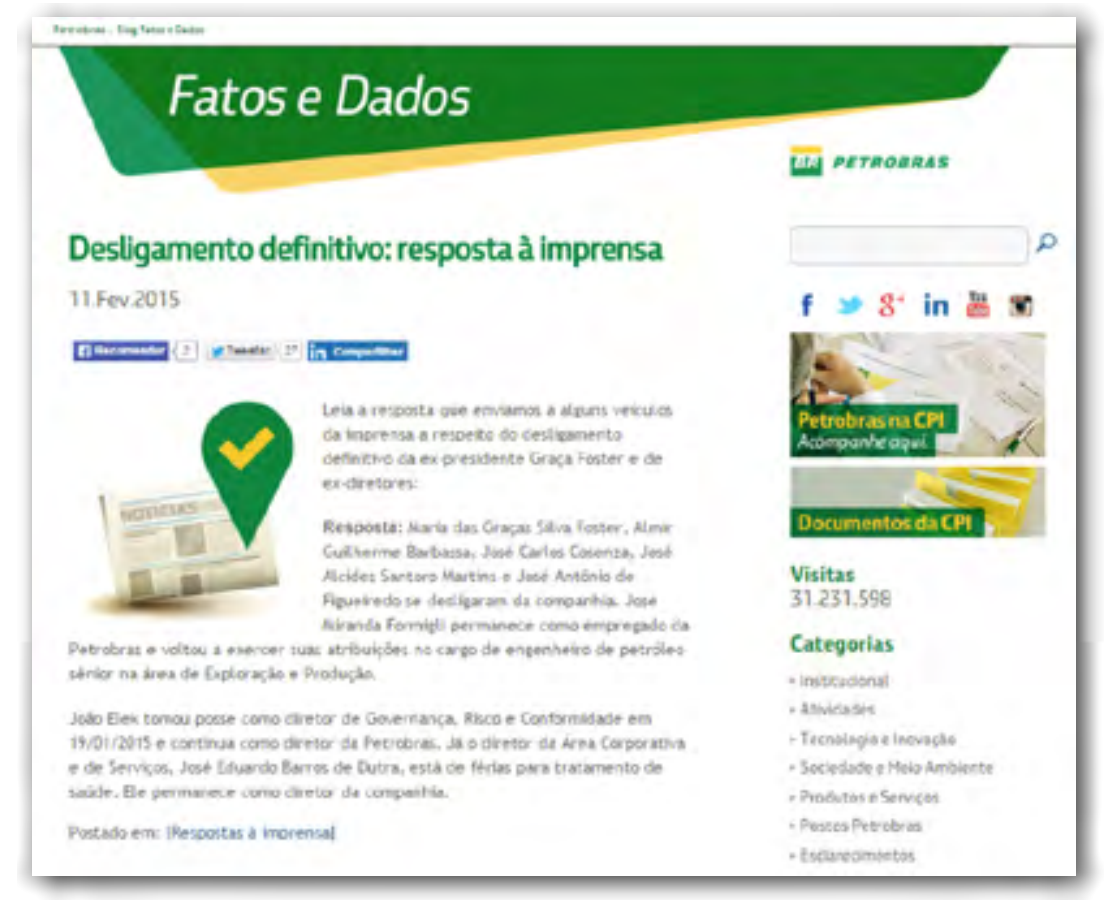

Fonte: blog Fatos e Dados

No período analisado, a companhia publicou cerca de 185 postagens no blog Fatos e Dados, sendo 30\% delas relacionadas a informações sobre a "Operação Lava-Jato" e seus desdobramentos. Mesmo a empresa mantendo o "Portal de transparência da Petrobras"11, o blog conta com duas seções especiais: "Petrobras na CPI" e "Documentos da CPI", espaços que evidenciam a busca pela transparência organizacional e o consequente resgate ou manutenção de credibilidade. Nessa direção, além de publicações de esclarecimentos/respostas à imprensa, há também a produção de conteúdo rotineiro como estratégia de visibilidade das ações, mostrando a normalidade das atividades. Se considerarmos o blog Fatos e Dados, no contexto da convergência midiática e de conteúdo, ressalta-se que ele é o principal fornecedor de conteúdos para as demais mídias sociais digitais nas quais a Petrobras está presente e para o próprio site oficial.

0 perfil da empresa no Twitter conta com 139 mil seguidores e é a mídia social com o maior volume de postagens, com uma média de cinco por dia, podendo ser repetidas algumas devido à natureza de atualização da timeline. No período analisado, foram cerca de 430 tweets, sendo 30\% deles relacionadas a informações sobre a "Operação Lava-Jato" e seus desdobramentos, seguindo a mesma lógica e as pautas do blog. No Twitter, segue-se uma perspectiva da distribuição de informação, em mão única, a fim de garantir a transparência das investigações e a visibilidade de ações, projetos e promoções.

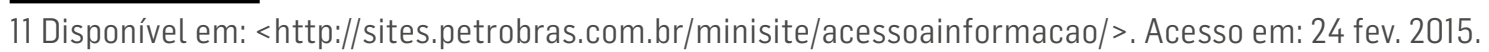


Figura 3 - Postagem na fanpage da Petrobras

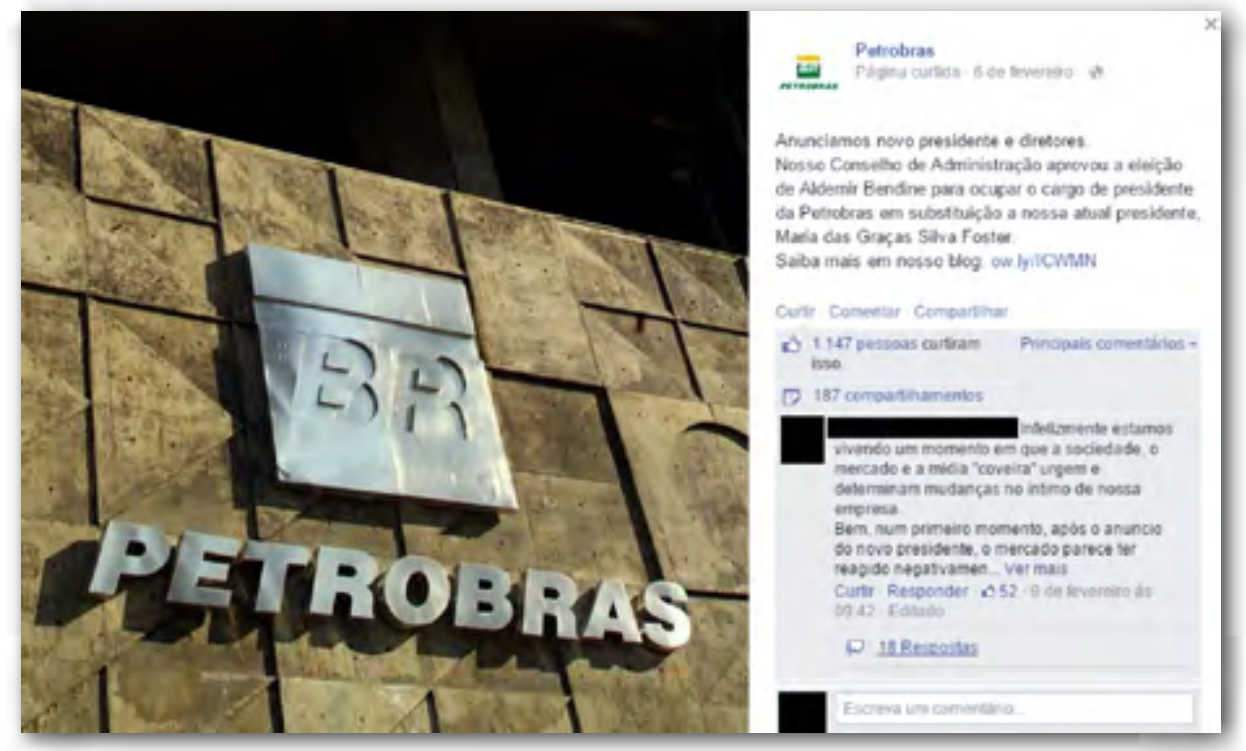

Fonte: Facebook.

Já a fanpage da Companhia, no Facebook, que conta com mais de 1 milhão e meio de fãs, trouxe poucas postagens. Em dois meses de observação, foram feitas 50 postagens, sendo $20 \%$ correspondentes às investigações de corrupção na empresa. A visibilidade nessa mídia social é bastante significativa, porém, também é maior a proporção de comentários, críticas, ofensas e ações de trolls² nas publicações da fanpage da Petrobras, limitando a interação. A própria companhia, na seção "Sobre" da fanpage, esclarece:

Seus comentários são muito bem-vindos. Entretanto, para que possamos manter uma discussão saudável e produtiva, estabelecemos as seguintes regras: 1) reservamo-nos o direito de deletar, sem aviso prévio: - conteúdos ofensivos a qualquer indivíduo, marca ou grupo social; - comentários que fujam ao tema do post, - links, comentários e outros conteúdos de autopromoção e vendas; 2) responderemos aos comentários, quando for pertinente, no momento mais adequado encontrado por nossa equipe de monitoramento. Nossos moderadores estão sempre atentos e fazendo o melhor possível para garantir a qualidade do conteúdo enviado para esta página. No entanto, se você perceber algum conteúdo ou material inapropriado ou que fira as regras desta comunidade, sinta-se à vontade para utilizar as ferramentas de notificação de spam.

Diante disso, evidencia-se o monitoramento e a avaliação/seleção de quais comentários serão respondidos, a fim de evitar embates entre interagentes e a empresa.

Figura 4 - Hotsite Superação $0^{13}$

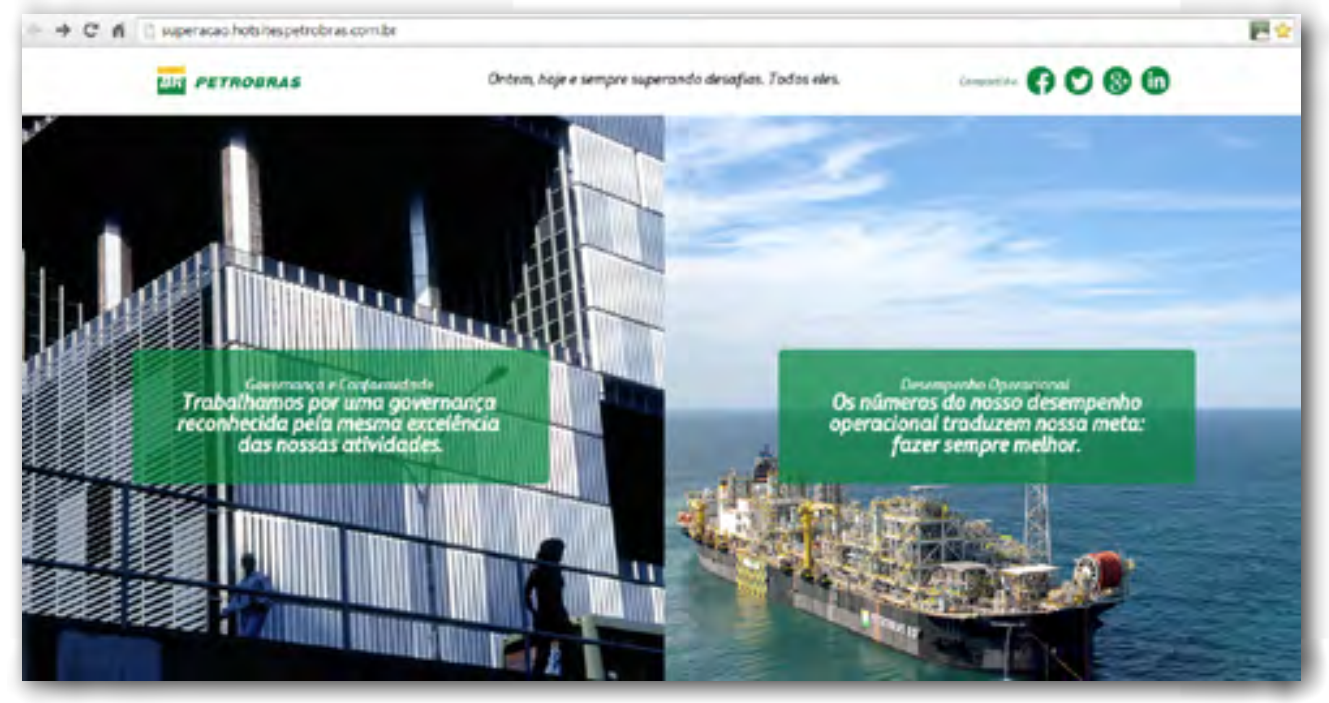

Fonte: Petrobras.

12 Interagentes que buscam desestabilizar as discussões na internet por meio de ofensas e spams.

13 Disponível em: <http://superacao.hotsitespetrobras.com.br/>. Acesso em 24 fev. 2015. 


\section{ANO 12 • NÚMERO $22 \cdot 1^{10}$ sem. 2015 - ORGANICOM \\ COMUNICAÇÃO DE CRISE EM MÍDIAS SOCIAIS DIGITAIS: UM ESTUDO DO TWITTER, DO FACEBOOK E DO BLOG CORPORATIVO DA PETROBRAS}

Além do uso de mídias digitais, a campanha "Superação", que teve início em 25 de janeiro de 2015, está presente sob forma de propaganda em mídia televisiva, radiofônica e impressa, em uma evidente estratégia de comunicação. A "Superação" busca colaborar com os objetivos da empresa, destacando o histórico de barreiras e desafios vencidos a fim de reestabelecer a confiança da sociedade na Petrobras. No entanto, em março, o Conar pediu a suspensão da veiculação do filme "Petrobras - Ontem, hoje e sempre superando desafios" na televisão, sob o argumento de a companhia estar infringindo 0 artigo 23 do conselho: "não abusar da confiança do consumidor, não explorar sua falta de experiência ou de conhecimento e não se beneficiar de sua credulidade"14. Em mais uma situação de crise, a Petrobras fez frente à imprensa e se valeu de dois de seus espaços institucionais digitais - Twitter e blog-para esclarecer o fato ao público, evitar boatos e distorções a respeito.

\section{CONSIDERAÇÕES FINAIS}

O uso das mídias sociais digitais representa um importante avanço na desintermediação, ou seja, da dispensa da mediação dos acontecimentos pelos tradicionais veículos de comunicação, pois a ambiência da internet dá voz às empresas, que potencializam as plataformas disponíveis a fim de proporcionar visibilidade aos seus resultados, interagir com públicos de interesse, fazer negócios e se retratarem.

Foi possível observar, por meio da análise realizada, um maior índice de interação, com respostas emitidas pela empresa, em postagens com pautas relacionadas ao dia a dia da organização, como, por exemplo, no processo seletivo de estagiários, sanando as dúvidas dos candidatos. Por outro lado, nas publicações mais polêmicas - que envolvem a "Operação LavaJato" - e que propiciam discussões e exposição de opiniões, a interação é quase nula. E isso se apresenta como uma clara estratégia de presença digital diante da ação de trolls.

A respeito do conteúdo, verificou-se, com este estudo, outra estratégia marcadamente presente nas mídias sociais digitais. Essa estratégia refere-se à busca contínua pela legitimação junto aos seus públicos, por meio da postagem de imagens, textos e links do hotsite da campanha "Superação" e de pautas que enfatizam o funcionamento normal das operações e a transparência dos acontecimentos que estão sendo apurados pela Polícia Federal.

Diante da crise de imagem e credibilidade que atravessa, constata-se que a Petrobras procura acompanhar e avaliar tanto o que é mostrado pela imprensa quanto o que os interagentes expressam na internet, no intuito de escolher a melhor forma de responder, esclarecer e amenizar a situação de crise vivida pela empresa atualmente.

É possível inferir da análise realizada que a comunicação organizacional da Petrobras se valeu deestratégias comunicacionais ao empreender ações digitais, informando, divulgando e deixando claro o seu posicionamento e sua política de comunicação em momentos de crise ou de normalidade.

\section{REFERÊNCIAS}

CONAR - Código Brasileiro de Autorregulamentação Publicitária. Disponível em: <http://www.conar.org.br/codigo/codigo. php>. Acesso em: 23 jun. 2015.

14 Disponível em: $<$ http://www.conar.org.br/codigo/codigo.php>. Acesso em: 23 jun. 2015. 
JOHNSON, Telma. Pesquisa social mediada por computador. questões, metodologia e técnicas qualitativas. Rio de Janeiro: E-papers, 2010.

MACHADO, Jones. A configuração das estratégias de comunicação da Petrobras no contexto de convergência midiática. 2012. 185f. Dissertação (Mestrado em Comunicação Midiática) - Universidade Federal de Santa Maria.

PÉREZ, Rafael Alberto. Pensar la estrategia: otra perspectiva. Buenos Aires: La Crujía, 2012.

SCOLARI, Carlos Alberto (Ed.). El fin de los medios masivos: el comienzo de un debate. Buenos Aires: La Crujía, 2009.

SIMÕES, Roberto Porto. Relações públicas: função política. 6. ed. - rev. e ampl. São Paulo: Summus, 2011.

TAPSCOTT, Don; TICOLL, David. A empresa transparente: como a era da transparência revolucionará os negócios. São Paulo: Makron Books, 2005.

THOMPSON, John B. A nova visibilidade. MATRIZes, ECA-USP, v. 1, n. 2, 2008.

ULMER, Robert R.; SELLNOW, Ttimothy L.; SEEGER, Matthew. Effective crisis communication: moving from crisis to opportunity. California: Sage, 2007.

YIN, Robert K. Estudo de caso: o planejamento e métodos. 2. ed. Porto Alegre: Bookman, 2005.

Artigo recebido em 16.03.2015 e aprovado em 01.06.2015. 